\title{
PENGARUH KUALITAS PELAYANAN, RELATIONSHIP MARKETING DAN CORPORATE SOCIAL RESPOSIBILITY TERHADAP LOYALITAS DAN KEPUASAN NASABAH BANK
}

\author{
YUNITA KURNIA SARI \\ PT Bank Rakyat Indonesia \\ yunitakurnia89@gmail.com
}

\begin{abstract}
This study aims to provide empirical evidence about the influence of Quality of Service, Relationship Marketing, Corporate Social Responsibility and customer satisfaction to customer loyalty in BRI branch Tebing Tinggi. By using the 150 respondents BRI customers Tebing Tinggi branch determination technique in 2016. Convenience sampling is sampling, that the sampling technique with a collection of information from members of the population that is easily available and able to provide such information. Mechanical testing of hypotheses using multiple regression analysis and path analysis.

$F$ test results showed that simultaneous all independ ent variables affect the customer loyalty. Based on test results can be concluded that customer satisfaction has a significant positive effect on customer satisfaction and customer loyalty. Relationship Marketing is not a significant effect on customer satisfaction and loyalty, while CSR significant effect on loyalty but has no significant effect on customer satisfaction. Further significant variable customer satisfaction has a significant positive effect on customer loyalty.
\end{abstract}

Keywords: Quality, Service, Relationship Marketing, Corporate Social Responsibility, Customer Satisfaction and Customer Loyalty

\begin{abstract}
ABSTRAK
Penelitian ini bertujuan untuk memberikan bukti empiris tentang pengaruh Kualitas layanan, Relationship Marketing, Corporate Social Responsibility dan Kepuasan nasabah terhadap Loyalitas nasabah di BRI Cabang Tebing Tinggi. Dengan menggunakan 150 responden nasabah BRI cabang Tebing Tinggi tahun 2016. Teknik penentuan sampling adalah Convenience Sampling, yaitu teknik pengambilan sampel dengan kumpulan informasi dari anggota-anggota populasi yang mudah diperoleh dan mampu menyediakan informasi tersebut. Teknik pengujian hipotesis menggunakan analisis regresi berganda dan analisis jalur.

Hasil uji $F$ menunjukan bahwa secara simultan semua variabel independen berpengaruh terhadap loyalitas nasabah. Berdasarkan hasil uji t dapat disimpulkan bahwa kepuasan nasabah berpengaruh signifikan positif terhadap kepuasan nasabah dan loyalitas nasabah. Relationship Marketing tidak berpengaruh signifikan terhadap kepuasan dan loyalitas nasabah, sedangkan CSR berpengaruh signifikan terhadap loyalitas tapi
\end{abstract}


tidak berpengaruh signifikan terhadap kepuasan nasabah. Selanjutnya variabel kepuasan nasabah berpengaruh signifikan positif terhadap loyalitas nasabah.

Kata Kunci: Kualitas layanan, Relationship Marketing, Corporate Social Responsibility, Kepuasan nasabah dan Loyalitas nasabah

Kepuasan layanan terhadap nasabah merupakan prioritas utama dalam bisnis perbankan. Oleh sebab itu, semua bank sangat mementingkan kualitas layanan kepada nasabah agar nasabah puas terhadap pelayanan yang diberikan oleh pihak bank. Persaingan antar bank menuntut peningkatan kinerja layanan dalam pemenuhan kebutuhan dan keinginan para nasabah agar nasabah merasa nyaman memakai jasa layanan dari bank. Kualitas pelayanan merupakan suatu kondisi dinamis yang berpengaruh dengan produk, jasa, manusia, proses dan lingkungan yang memenuhi atau melebihi harapan (Tjiptono, 2002). Hal tersebut membuat bank harus memiliki strategi pemasaran yang baik supaya para nasabah mendapatkan kualitas pelayanan yang baik dari bank agar tercipta kepuasan nasabah saat menggunakan jasa yang disediakan oleh bank.

Pelaku bisnis bank di Indonesia tentunya mengupayakan loyalitas nasabah melalui pembentukan kepuasan nasabah setelah penggunaan produknya. Komitmen yang tinggi dapat diupayakan bila nasabah merasa puas pada suatu bank. Nasabah yang puas akan menjadi nasabah yang loyal, sedangkan nasabah yang tidak puas akan berpindah pada bank lain. Rendahnya komitmen dan tingkat konsistensi yang mempengaruhi preferensi dan kesetiaan nasabah (Anwar, 2007:15).

Hasil penelitian Madjid (2013) menunjukkan bahwa kepuasan nasabah memiliki pengaruh yang signifikan terhadap kepercayaan dan loyalitas nasabah. Selain itu, kepercayaan nasabah berpengaruh positif dan signifikan terhadap loyalitas nasabah dan juga kepercayaan nasabah memediasi antara kepuasan nasabah dan loyalitas nasabah. Sedangkan penelitian yang dilakukan oleh Agusta dan Dedy (2011) menunjukkan bahwa kepercayaan dan kepuasan nasabah berpengaruh terhadap loyalitas nasabah dengan tingkat korelasi yang sangat erat. Ada banyak perusahaan jasa perbankan di Indonesia yang mempunyai banyak nasabah. Bank Rakyat Indonesia (BRI) adalah salah satu bank milik pemerintah yang terbesar dan tersebar di Indonesia. Bank Rakyat Indonesia merupakan sebuah perusahaan yang bergerak dibidang perbankan yang memiliki tujuan untuk menjadi bank komersial terkemuka yang selalu mengutamakan kepuasan nasabah. Seperti visinya, BRI kini sudah memiliki 19 kantor wilayah, 463 kantor cabang, 603 kantor cabang pembantu, 5362 BRI Unit, 2557 Teras BRI, dan 598 kantor kas yang tersebar diseluruh pelosok Indonesia.

Dengan jumlah nasabah sebanyak sekitar 74,8 juta diseluruh Ind onesia, Bank BRI juga semakin mendekatkan diri kepada nasabahnya. BRI juga menawarkan sejumlah kemudahan bagi pengguna jasa perbankan dengan menyediakan jaringan e-channel yang berkualitas. Nasabah BRI dapat melakukan transaksi perbankan di ATM BRI yang tersebar di seluruh unit kerja BRI seluruh Indonesia dan tempat-tempat strategis lainnya. Jumlah ATM BRI yang dapat diakses oleh pemegang BRI Card adalah sebanyak 6300 ATM BRI, 18.500 ATM Link, 22.000 ATM Bersama, 17.427 ATM PRIMA, 2.075 ATM MEPS (BANKCARD), serta 800.000 ATM berlogo Cirrus di seluruh dunia. Selain ATM yang sudah tersebar diseluruh lokasi-lokasi strategis, dengan dibekali teknologi yang unggul Bank BRI juga memfasilitasi nasabahnya agar dapat bertransaksi dengan lebih mudah menggunakan sms banking dan internet banking BRI, sehingga nasabah dapat melakukan transaksi secara real time online, cepat, mudah, serta dapat dilakukan kapan saja dan dimana saja. 
Perwujudan strategi transformasi BRI dilakukan melalui perluasan jangkauan layanan yang berkualitas dengan penguatan e-channel, BRILink, mobile services, digital banking innovation, produk dan jasa keuangan, serta Sedangkan jaringan konvesional diperluas melalui penambahan unit kerja maupun automobile offices: Teras keliling, eBuzz, serta sentra Layanan Prioritas dan pembukaan unit kerja luar negeri. BRI juga menyadari bahwa masih banyak potensi di daerah-daerah remote area yang belum bankable, oleh karena itu pada tanggal 4 agustus 2015 BRI resmi meluncurkan Teras BRI kapal untuk menjangkau masyarakat pesisir kepulauan yang selama ini belum dapat menikmati layanan perbankan. BRI mencoba berinovasi dengan menghadirkan Teras Kapal BRI Bahtera Seva yang memungkinkan untuk mencapai hingga ke daerahdaerah yang sulit terjangkau. Tak hanya berhenti sampai disitu, BRI terus memperbaiki dan meningkatkan kualiatas pelayanannya dengan mengembangkan proyek infrastruktur jaringan komunikasi - satelit BRI dan Fiber optik dengan membeli sebuah satelit yang diberi nama BRISAT yang kini sudah mengudara dan menjadikan BRI sebagai satu-satunya bank yang sudah memiliki satelit sendiri untuk memperlancar operasional perbankan. Tentunya hal ini merupakan suatu nilai positif dan ung gul bagi bank BRI bila dibandingkan dengan bank-bank lain.

Upaya-upaya tersebut dilakukan BRI semata-mata demi meningkatkan pelayanan yang nantinya akan menimbulkan kepuasan dan loyalitas nasabah. Dengan jumlah nasabah yang banyak, BRI memiliki suatu tantangan besar untuk terus memberikan kualitas layanan yang maksimal demi kepuasan nasabah. Al-Rousan et al. (2010) yang menyatakan bahwa perusahaan jasa harus berupaya untuk mempertahankan kualitas pelayanan yang unggul melebihi pesaing mereka untuk memperoleh dan mempertahan kepuasan pelanggan.

Selain kepuasan nasabah dan kualitas pelayanan, salah satu strategi yang dapat dijadikan alat untuk menjaga loyalitas nasabah adalah dengan menciptakan relationship marketing yang baik. Menurut Kotler dan Amstrong (2006:194) relatioship marketing adalah sebuah proses menciptakan, mempertahankan, dan meningkatkan hubungan yang kuat dan bernilai tinggi dengan pelanggan serta pihak yang berkepentingan lainnya. Pemasaran yang berbasis pada hubungan dengan pelanggan harus diikuti adanya penguasaan jaringan yang kuat baik dari sisi suplier, distributor, atau mitra bisnis terutama pelanggan, bahkan jaring an pada stakeholder dan pesaing. Kekuatan elemen pemasaran yang berbasis pada hubungan dengan pelanggan menjadi kekuatan yang cukup dominan pada kondisi pasar yang semakin customized.

Relationship marketing adalah salah satu cara bagaimana perusahaan menjalin hubungan baik dengan pelanggannya agar melakukan pembelian kembali. Chan (2003: 6) mengartikan relationship marketing sebagai pengenalan nasabah secara lebih dekat dan memuasakan dengan menciptakan komunikasi dua arah dengan mengelola suatu hubungan yang saling menguntungkan antara nasabah dan perusahaan. Melalui relationship marketing Ndubisi (2007) menyatakan bahwa perusahaan lebih banyak memanfaatkan hubungan yang kuat antara perusahaan dengan pelanggan untuk mendapatkan informasi berharga mengenai cara terbaik untuk melayani pelanggan dan menjaga agar tidak berpindah ke pesaing.

Bank Rakyat Indonesia merupakan perusahaan yang bergerak dibidang jasa perbankan yang memiliki tujuan untuk menjadi bank komersial terkemuka yang selalu mengutamakan kepuasan nasabah. Seperti visinya, BRI kini sudah memiliki nasabah sebanyak 52 juta lebih di seluruh Indonesia. Hingga kini BRI terus meningkatkan kinerja, layanan, dan produk demi mempermudah transaksi nasabah. Dengan nasabah yang banyak, bank BRI memiliki suatu tantangan besar untuk terus memberikan kualitas layanan yang maksimal demi kepuasan nasabah. Selain mempertahankan kualitas layanan BRI dengan nasabah yang banyak juga memiliki tanggung jawab sosial yang tinggi terhadap masyarakat. BRI juga memiliki program CSR yang ditujukan untuk masyarakat guna memenuhi tanggung jawab sosial perusahaan yang mempunyai banyak nasabah. Program CSR BRI ditujukan untuk meningkatkan 
kesejahteraan bidang lingkungan, sosial dan ekonomi masyarakat. Menurut Kotler dan Lee (2005) CSR yang diterapkan secara tepat baik dibidang sosial, ekonomi, maupun lingkungan dapat memberikan banyak keuntungan bagi perusahaan salah satunya adalah loyalitas pelanggan. Nareeman dan Hassan (2013), menunjukan bahwa CSR berpengaruh positif dan signifikan terhadap kepuasan dan loyalitas pelanggan. Dengan adanya CSR dalam sebuah perusahaan membuat perusahaan tersebut lebih memahami dan meningkatkan pengetahuan khusus terhadap pelanggannya, hal ini akan berdampak pada kepuasan pelanggan (Mcwilliams, 2006).

Al-Rousan et al. (2010) yang menyatakan bahwa perusahaan jasa harus berupaya untuk mempertahankan kualitas pelayanan yang unggul melebihi pesaing mereka untuk memperoleh dan mempertahan kepuasan pelanggan. Dengan peningkatan kualitas layanan yang terus ditingkatkan para nasabah akan tetap menggunakan jasa bank karena nasabah merasa puas terhadap pelayanan yang deberikan oleh bank. Selain itu relationship marketing merupakan bagian yang menjadi perhatian perusahaan penyedia jasa, dimana perusahaan mengevaluasi kriteria dari pelanggan dalam menilai aspek jasa. Dengan relationship marketing yang baik antara BRI dan para nasabah akan menimbulkan rasa puas dari para nasabah sehingga akan menumbukna loyalitas dari para nasabah BRI. Tan dan Komaran (2006), mengemukakan bahwa kegiatan CSR yang dilakukan oleh perusahaan dapat berpengaruh secara tidak langsung terhadap permintaan konsumen melalui tingkat kepuasan dan ingatan pelanggan yang tinggi terhadap suatu barang ataupun jasa.

\section{TELAAH PUSTAKA}

\section{Pengertian Kualitas Layanan}

Menurut Payne (2009:74), pelayanan adalah rasa menyenangkan atau tidak menyenangkan yang oleh penerima pelayanan pada saat memperoleh pelayanan. Payne juga mengatakan bahwa pelayanan pelanggan mengandung pengertian:

1. Segala kegiatan yang dibutuhkan untuk menerima, memproses, menyampaikan dan memenuhi pesanan pelanggan dan untuk menindak lanjuti setiap kegiatan yang mengandung kekeliruan.

2. Ketepatan waktu dan reliabilitas penyampaian jasa kepada pelanggan sesuai dengan harapan mereka.

3. Serangkaian kegiatan yang meliputi semua bidang bisnis yang terpadu untuk menyampaikan produk-produk dan jasa tersebut sedemikian rupa sehingga dipersepsikan memuaskan oleh pelanggan dan merealisasikan pencapaian tujuan-tujuan perusahaan.

4. Total pesanan yang masuk dan seluruh komunikasi dengan pelanggan. Penyampaian produk kepada pelanggan tepat waktu dan akurat dengan segala tindak lanjut serta tanggapan keterangan yang akurat.

Menurut Lewis \& Booms (1993) dalam Tjiptono dan Chandra (2011: 180) mendefinisikan kualitas jasa sebagai ukuran seberapa bagus tingkat layanan yang diberikan mampu sesuai dengan ekspetasi pelanggan. Keberhasilan perusahaan dalam memberikan pelayanan yang berkualitas dapat ditentukan dengan pendekatan service quality yang telah dikembangkan oleh Parasuraman, Berry dan Zenthaml (Lupiyoadi,2014:181) yang mengemukakan bahwa terdapat lima dimensi utama yang disusun sesuai tingkat kepentingan relatifnya sebagai berikut:

1. Reliabilitas (Reliability)

2. Daya Tanggap (Responsiveness)

3. Jaminan (Assurance)

4. Empati (Empathy)

5. Bukti Fisik (Tangibles) 


\section{Relationship Marketing}

Menurut Kotler dan Amstrong (2006:194) relatioship marketing adalah sebuah proses menciptakan, mempertahankan, dan meningkatkan hubungan yang kuat dan bernilai tinggi dengan pelanggan serta pihak yang berkepentingan lainnya. Hubungan ini bersifat partnership, bukan sekedar hubungan antara penjual dan pembeli. Ini berarti tujuan jangka panjang adalah menghasilkan keuntungan yang terus menerus dari suatu kelompok pelanggan yaitu pelanggan yang sekarang dan juga pelanggan yang baru.Untuk dapat mempertahankan eksistensinya sebuah perusahaan membutuhkan pembinaan hubungan yang baik dengan para pelanggannya. Hubungan yang baik akan menumbuhkan kesan yang baik bagi pelanggan. Menurut Utami (2006:139) hubungan pemasaran adalah suatu cara untuk mengatasi permasalahan melalui penyampaian secara langsung dan berbicara secara terperinci kepada pelanggan mengenai penyelesaian yang terbaik. Tujuannya membangun dasar kesetiaan pelanggan yang sering kali berguna bagi perusahaan.

\section{Corporate Social Resposibility}

Menurut Griffin (2008) tanggung jawab sosial merupakan usaha suatu bisnis untuk dapat menciptakan keseimbangan komitmennya terhadap kelompok maupun individu dalam lingkungan entitas bisnis tersebut yang meliputi konsumen, bisnis lain, karyawan dan investor. CSR merupakan kegiatan social, ekonomi dan lingkungan yang dilakukan oleh perusahaan dan merupakan tanggungjawab yang harus dilakukan oleh perusahaan disamping perannya sebagai penyedia laporan keuangan kepada pemilik modal.

Kotler dan Lee, 2005 membagi kategori aktivitas C SR sebagai berikut:

1. Cause Promotions

2. Cause-Related Marketing

3. Corporate Social Marketing

4. Corporate Phylantrhropy

5. Community Volunteering

6. Social Responsibility Business Practice

\section{Kepuasan Nasabah/ Konsumen (Customer Satisfaction)}

Menurut Kotler (2005) secara umum mendefinisikan kepuasan konsumen sebagai perasaan senang atau kecewa seseorang yang telah muncul setelah membandingkan antara kinerja (hasil) produk yang dipikirkan terhadap kinerja (hasil) yang diharapkan. Jika kinerja berada di bawah harapan, konsumen tidak akan puas. jika kinerja memenuhi harapan, konsumen akan puas. Jika kinerja melebihi harapan, konsumen amat puas atau senang. Konsumen yang puas cenderung akan memberikan referensi yang baik terhadap produk atau jasa kepada orang lain.

\section{Loyalitas Nasabah}

Menurut Griffin (2008:5), Customer loyalty adalah suatu perilaku yang ditunjukkan dengan pembelian rutin, didasarkan padaunit pengambilan keputusan. Loyalitas konsumen terhadap suatu barang atau jasa yang ditawarkan oleh suatu perusahaan yang tercermin dari kebiasaan konsumen dalam melakukan pembelian barang dan jasa secara terus-menerus harus selalu diperhatikan oleh perusahaan dengan demikian perusahaan perlu mengamati loyalitas konsumen untuk dapat memenuhi kebutuhan mereka.

\section{Pengembangan Hipotesis}

\section{Pengaruh kualitas pelayanan pada kepuasan nasabah}

Zafar et al. (2012) menemukan bahwa ada hubungan positif dan signifikan antara kualitas pelayanan dan kepuasan pelanggan. Menurut Bedi dalam Ming et al. (2010) pengiriman layanan yang berkualitas tinggi adalah suatu keharusan 
untuk mencapai kepuasan pelanggan. Penelitian tersebut sejalan dengan Naeem dan Saif (2009) yang menemukan bahwa kepuasan pelanggan adalah hasil dari kualitas pelayanan. Sanka (2012) menyatakan ada korelasi positif dan signifikan antara dimensi kualitas pelayanan dengan kepuasan pelanggan. Semakin baik kualitas layanan maka akan semakin ting gi tingkat kepuasan nasabah. Dari uraian tersebut maka dirumuskan hipotesis sebagai berikut:

H1: Kualitas pelayanan berpengaruh positif dan signifikan pada kepuasan nasabah bank BRI.

\section{Pengaruh relationship marketing pada kepuasan nasabah}

Relationship marketing merupakan penciptaan nilai dan pemeliharaan hubungan tahan lama antara perusahaan dengan pelanggan sehingga tercipta kepuasan bagi kedua belah pihak dikemukakan Ndubisi Jesri (2005). Penelitian Sutanto dan Japarianto (2013) menujukkan bahwa relationship marketing memiliki pengaruh yang positif dan signifikan dalam memberikan kepuasan kepada nasabah. Hubungan yang tercipta secara harmonis antara nasabah dan bank akan membuat nasabah merasa puas akan pelayanan jasa yang diberikan oleh bank. Relationship marketing bertujuan untuk membangun hubungan yang memuaskan dalam jangka panjang dengan perusahaan. Semakin baik relationship marketing maka akan semakin tinggi tingkat kepuasan nasabah. Dari uraian tersebut maka dirumuskan hipotesis sebagai berikut:

H2: Relationship marketing nasabah berpengaruh positif dan signifikan terhadap kepuasan nasabah bank BRI

\section{Pengaruh CSR pada kepuasan nasabah}

Nareeman dan Hassan (2013), mengungkapkan bahwa dampak CSR terhadap kepuasan pelanggan dan retensi menunjukkan bahwa CSR berpengaruh positif dan signifikan terhadap kepuasan dan loyalitas pelanggan. Tan dan Komaran (2006), juga mengatakan kegiatan kedermawanan yang dilakukan oleh perusahaan dapat berpengaruh secara tidak langsung terhadap permintaan konsumen melalui tingkat kepuasan dan ingatan pelanggan yang tinggi terhadap suatu barang ataupun jasa. Dengan adanya CSR dalam sebuah perusahaan membuat perusahaan tersebut lebih memahami dan meningkatkan pengetahuan khusus terhadap pelanggannya, hal ini akan berdampak pada kepuasan pelanggan (Mcwilliams, 2006). Athanassopoulos (2000) mengatakan bahwa nilai CSR berdampak terhadap kepuasan pelanggan. Semakin tinngi implementasi C SR maka akan semakin tinggi tingkat kepuasan nasabah. Dari uraian tersebut maka dirumuskan hipotesis sebagai berikut:

H3: CSR berpengaruh positif dan signifikan pada kepuasan nasabah bank BRI.

\section{Pengaruh kualitas pelayanan pada loyalitas nasabah}

Hasil penelitian Akbar dan Parves (2009) menunjukkan terdapat hubungan yang positif dan signifikan antara kualitas pelayanan terhadap loyalitas pelanggan. Kumar et al. (2009) menyatakan bahwa kualitas pelayanan yang baik akan menghasilkan kepuasan pelanggan yang tinggi yang dapat meningkatkan loyalitas pelanggan. Dalam mengambil kebijakan untuk meningkatkan loyalitas nasabah, kualitas pelayanan perlu diperhatikan karena variabel ini berpengaruh positif dan signifikan terhadap loyalitas nasabah (Yani, 2004 ). Semua atribut kualitas pelayanan berpengaruh positif terhadap kepuasan pelanggan dan kepuasan pelanggan berkaitan langsung dengan loyalitas pelanggan (Siddiqi, 2011). Ehigie dalam Ladhari et al. (2011) juga menemukan bahwa kualitas 
pelayanan dan kepuasan adalah prediktor penting loyalitas nasabah bank. Semakin baik kualitas layanan maka akan semakin tinggi loyalitas nasabah. Dari uraian tersebut maka dirumuskan hipotesis sebagai berikut:

H4: Kualitas pelayanan berpengaruh positif dan signifikan pada loyalitas Nasabah bank BRI.

\section{Pengaruh relationship marketing nasabah pada loyalitas nasabah}

Ndubisi (2007) menyatakan bahwa kunci pokok dari relationship marketing adalah komunikasi, kepercayaan, komitmen, dan penyelesaian masalah. Dengan terpenuhinya kunci pokok relationship marketing yaitu komunikasi, kepercayaan, komitmen, dan penyelesaian masalah maka akan meningkatkan hubungan yang baik antara bank dan nasabah. Relationship marketing merupakan salah satu cara bagaimana perusahaan menjalin hubungan baik dengan pelanggannya agar nasabah tetap loyal terhadap jasa-jasa yang ditawarkan oleh bank. Penelitian Silmi (2012) menemukan bahwa relationship marketing memiliki pengaruh yang positif dan signifikan loyalitas nasabah. Sama dengan penelitian yang dilakukan oleh Peyman, Freyedon Ahmadi dan Motreza Fatehipoor (2013) menemukan bahwa relationship marketing berpengaruh terhadap loyalitas nasabah. Semakin baik relationship marketing yang dilakukan oleh suatu bank maka semakin besar loyalitas dari para nasabah. Dari uraian tersebut maka dirumuskan hipotesis sebagai berikut:

H5: Relationship marketing berpengaruh positif dan signifikan pada loyalitas nasabah bank BRI

\section{Pengaruh CSR pada loyalitas nasabah}

CSR adalah wujud dari tanggung jawab perusahaan kepada lingkungan masyarakat. Melalui program CSR perusahaan menunjukkan tanggung jawab sosialnya kepada masyarakat dengan cara ikut membangun kondisi lingkungan sosial dan ekonomi masyarakat di sekitarnya. Dengan wujud pelaksanaan CSR di masyarakat oleh perusahaan maka para pelanggan akan mengetahui bahwa perusahaan memiliki manfaat terhadap masayarakat disekitarnya sehingga akan memunculkan loyalitas pelanggan kepada produk-produk perusahaan. Andreas Lako (2011) menyatakan bahwa CSR tidak hanya sekadar sebagai aktivitas kedermawan (charity) atau aktivitas saling mengasihi (stewardship) yang bersifat sukarela namun lebih dari itu CSR juga harus dipahami sebagai KAK yang melekat dan hidup dalam suatu sistem bisnis. Menurut Seravina (2008), tanggapan pelanggan terhadap aktivitas Corporate Social Responsibility memiliki pengaruh positif terhadap loyalitas pelanggan. Semakin baik implementasi CSR yang dilakukan oleh suatu bank maka semakin besar loyalitas dari para nasabah. Dari uraian tersebut maka dirumuskan hipotesis sebagai berikut:

H6: CSR berpengaruh positif dan signifikan pada loyalitas nasabah bank BRI

\section{Pengaruh kepuasan nasabah pada loyalitas nasabah}

Bowen dan Chen (2001) menemukan bahwa kepuasan pelanggan berpengaruh positif dan signifikan terhadap loyalitas pelanggan. Penelitian ini juga sejalan dengan penelitian yang dilakukan oleh Molaee et al. (2013) dan Anggraeni (2012) menyatakan bahwa kepuasan pelanggan berpengaruh positif dan signifikan terhadap loyalitas pelanggan. Odin et al., (2001) mengatakan bahwa kepuasan pelanggan mempengaruhi perilaku pembeli, dimana pelanggan yang puas cenderung menjadi pelanggan yang loyal, namun pelanggan yang loyal tidak perlu puas. Loyalitas berarti kemampuan perusahaan memposisikan 
produknya di benak pelanggan, dimana perusahaan berusaha menganggap pelanggan. Semakin baik kepuasan nasabah maka akan semakin tinggi loyalitas nasabah. Dari uraian tersebut maka dirumuskan hipotesis sebagai berikut:

H7: Kepuasan nasabah berpengaruh positif dan signifikan pada loyalitas nasabah bank BRI.

\section{METODE PENELITIAN}

\section{Rancangan Penelitian}

Rancangan penelitian ini bertujuan untuk mengukur tingkat kepuasan pelanggan dan loyalitas pelanggan nasabah Bank Rakyat Indonesia Kantor Cabang Tebing Tinggi. Penelitian ini termasuk klasifikasi penelitian survey deskriptif yaitu penelitian yang mengambil sampel dari populasi dan menggunakan kuesioner sebagai instrument pengumpulan data utama.

\section{Definisi Operasional dan Pengukuran}

\begin{tabular}{|c|c|c|c|}
\hline $\begin{array}{l}\text { Variabel } \\
\text { Penelitian }\end{array}$ & Definisi Variabel & Indikator & Skala \\
\hline $\begin{array}{l}\text { Kualitas } \\
\text { Layanan } \\
\text { (Variabel } \\
\text { X1) }\end{array}$ & $\begin{array}{l}\text { Kualitas pelayanan sebagai setiap } \\
\text { tindakan atau kegiatan yang dapat } \\
\text { ditawarkan oleh satu pihak kepada pihak } \\
\text { lain, pada dasarnya tidak berwujud dan } \\
\text { tidak mengakibatkan kepemilikan } \\
\text { apapun (Lupiyoadi, 2006) }\end{array}$ & $\begin{array}{l}\text { a. Tangible } \\
\text { b. Reliabel } \\
\text { c. Responsiveness } \\
\text { d. Assurance } \\
\text { e. Emphaty }\end{array}$ & Likert \\
\hline $\begin{array}{l}\text { Relationship } \\
\text { marketing } \\
\text { (X2) }\end{array}$ & $\begin{array}{l}\text { Sebuah proses menciptakan, } \\
\text { mempertahankan, dan meningkatkan } \\
\text { hubungan yang kuat dan bernilai tinggi } \\
\text { dengan pelanggan serta pihak yang } \\
\text { berkepentingan lainnya Kotler dan } \\
\text { Amstrong (2006:194) }\end{array}$ & $\begin{array}{ll}\text { a. } & \text { Trust } \\
\text { b. } & \text { Commitment } \\
\text { c. } & \text { Communication } \\
\text { d. } & \text { Conflict handling }\end{array}$ & Likert \\
\hline $\begin{array}{l}\text { CSR } \\
(X 3)\end{array}$ & $\begin{array}{l}\text { Tanggung jawab sosial merupakan usaha } \\
\text { suatu bisnis untuk dapat menciptakan } \\
\text { keseimbangan komitmennya terhadap } \\
\text { kelompok maupun individu dalam } \\
\text { lingkungan entitas bisnis tersebut yang } \\
\text { meliputi konsumen, bisnis lain, } \\
\text { karyawan dan investor. } \\
\text { Griffin (2008) }\end{array}$ & $\begin{array}{l}\text { a. Dimensi Sosial } \\
\text { b. Dimensi Ekonomi } \\
\text { c. Dimensi } \\
\text { Lingkungan }\end{array}$ & Likert \\
\hline $\begin{array}{c}\text { Kepuasan } \\
\text { Nasabah } \\
(Y 1)\end{array}$ & $\begin{array}{l}\text { Kepuasan Pelanggan adalah perbedaan } \\
\text { antara tingkat } \\
\text { kepentingan dan kinerja atau hasil yang } \\
\text { dirasakan. Rangkuti (2004: } \\
\text { 56) }\end{array}$ & $\begin{array}{l}\text { a. Harapan } \\
\text { pelanggan } \\
\text { b. Kinerja } \\
\text { perusahaan }\end{array}$ & Likert \\
\hline $\begin{array}{l}\text { Loyalitas } \\
\text { Nasabah } \\
\text { (Variabel } \\
\text { Y2) }\end{array}$ & $\begin{array}{l}\text { Loyalitas pelanggan merupakan } \\
\text { komitmen pelanggan terhadap toko, } \\
\text { merk ataupun pemasok yang didasarkan } \\
\text { atas sikap positif yang tercermin dalam } \\
\text { bentuk pembelian berulang secara } \\
\text { konsisten (Tjiptono, 2007) }\end{array}$ & $\begin{array}{l}\text { a. Word of mouth } \\
\text { communications } \\
\text { b. Future Repurchase } \\
\text { Intention } \\
\text { c. Complaining } \\
\text { behavior } \\
\text { d. Price sensitive }\end{array}$ & Likert \\
\hline
\end{tabular}




\section{HASIL DAN PEMBAHASAN}

\section{Analisis Regresi Model 1}

Uji parsial digunakan untuk menguji pengaruh Kualitas Iayanan $(\mathrm{KL})$, Relationship Marketing (RM) dan Corporat Social Responsibility (CSR) terhadap Kepuasan nasabah (KP) secara parsial. Uji parsial dalam penelitian ini dilakukan untuk mengetahui pengaruh masing-masing variabel kualitas layanan, Relationship Marketing dan CSR secara parsial terhadap kepuasan nasabah BRI. Hasil analisis statistik uji t dapat dilihat sebagai berikut:

Tabel 1. Uji Signifikansi Parameter Individual (Uji t) Coefficients $^{\mathrm{a}}$

\begin{tabular}{|c|c|c|c|c|c|c|}
\hline & \multirow[b]{2}{*}{ Model } & \multicolumn{2}{|c|}{$\begin{array}{l}\text { Unstandardized } \\
\text { Coefficients }\end{array}$} & \multirow{2}{*}{$\begin{array}{c}\text { Standardized } \\
\text { Coefficients } \\
\text { Beta } \\
\end{array}$} & \multirow[b]{2}{*}{$\mathrm{T}$} & \multirow[b]{2}{*}{ Sig. } \\
\hline & & B & Std. Error & & & \\
\hline \multirow[t]{4}{*}{1} & (Constant) & 8.809 & 3.001 & & 2.935 & .004 \\
\hline & $\mathrm{KL}$ & .105 & .028 & .302 & 3.781 & .000 \\
\hline & RM & -.007 & .057 & -.010 & -.129 & .897 \\
\hline & CSR & .022 & .047 & .038 & .482 & .631 \\
\hline
\end{tabular}

a. Dependent Variable: KP

Sumber: Data Primer yang diolah, 2016

\section{Analisis Regresi Model 2}

Uji parsial digunakan untuk menguji pengaruh Kualitas Iayanan (KL), Relationship Marketing (RM), Corporat Social Responsibility (CSR) dan Kepuasan nasabah (KP) terhadap Loyalitas nasabah (LY) secara parsial. Uji parsial dalam penelitian ini dilakukan untuk mengetahui pengaruh masing-masing variabel Kualitas layanan, Relationship Marketing, Corporat Social Responsibility dan Kepuasan nasabah secara parsial terhadap Loyalitas nasabah BRI. Hasil analisis statistik uji t dapat dilihat sebagai berikut:

\section{Tabel 2. Uji Signifikansi Parameter Individual (Uji t)}

\section{Coefficients $^{\mathrm{a}}$}

\begin{tabular}{|c|c|c|c|c|c|c|}
\hline & \multirow[b]{2}{*}{ Model } & \multicolumn{2}{|c|}{$\begin{array}{l}\text { Unstandardized } \\
\text { Coefficients }\end{array}$} & \multirow{2}{*}{$\begin{array}{c}\text { Standardized } \\
\text { Coefficients } \\
\text { Beta }\end{array}$} & \multirow[b]{2}{*}{$\mathrm{T}$} & \multirow[b]{2}{*}{ Sig. } \\
\hline & & B & Std. Error & & & \\
\hline \multirow[t]{5}{*}{1} & (Constant) & -4.336 & 1.884 & & -2.302 & .023 \\
\hline & $\mathrm{KL}$ & .064 & .018 & .170 & 3.617 & .000 \\
\hline & RM & .009 & .035 & .012 & .264 & .792 \\
\hline & CSR & .067 & .028 & .105 & 2.365 & .019 \\
\hline & $\mathrm{KP}$ & .838 & .050 & .771 & 16.607 & .000 \\
\hline
\end{tabular}

a. Dependent Variable: LY

Sumber: Data Primer yang diolah, 2016 


\section{Kualitas Layanan dan Kepuasan Nasabah}

Dari hasil uji statistik variabel kualitas layanan mempunyai signifikasi sebesar 0,000 yang berarti nilai siginfikasi kualitas layanan lebih kecil dari 0,05 dengan nilai unstandardized coefficients beta sebesar 0,105 sehingga variabel kualitas layanan berpengaruh signifikan positif terhadap kepuasan nasabah. Hipotesis 1 diterima dengan arah pengaruh positif, sesuai dengan hipotesis 1 yang menyatakan kualitas layanan berpengaruh positif signifikan terhadap kepuasan nasabah. Semakin besar nilai kualitas pelayanan maka akan semakin tinggi tingkat kepuasan nasabah.

Hasil penelitian ini sesuai dengan penelitian Zafar et al. (2012) menemukan bahwa ada hubungan positif dan signifikan antara kualitas pelayanan dengan kepuasan pelanggan. Dengan pelayanan yang baik maka pelanggan juga akan merasa puas dengan jasa yang diberikan oleh bank. Bedi dalam Ming et al. (2010) layanan yang berkualitas tinggi adalah suatu keharusan untuk mencapai kepuasan pelanggan. Dengan kualitas layanan yang semakin baik maka nasabah BRI akan semakin puas dengan pelayanan BRI. Di BRI cabang Tebing Tinggi sendiri selalu meningkatkan layanan bagi para nasabahnya mulai dari jumlah karyawan yang memadai, hingga peningkatan prasarana bank seperti fasilitas antrian yang nyaman, mesin ATM yang jumlahnya mencukupi dan kebersihan serta kenyamanan yang menjadi ciri khas ketika memasuki kantor BRI cabang Tebing Tinggi.

\section{Relationship Marketing dan Kepuasan Nasabah}

Dari hasil uji statistik variabel Relationship Marketing mempunyai signifikasi sebesar 0,897 yang berarti nilai siginfikasi kualitas layanan lebih besar dari 0,05 dengan nilai unstandardized coefficients beta sebesar -0,007 sehing a variabel Relationship Marketing tidak berpengaruh signifikan terhadap kepuasan nasabah. Hipotesis 2 ditolak karena tidak sesuai dengan hipotesis 1 yang menyatakan Relationship Marketing berpengaruh positif signifikan terhadap kepuasan nasabah.

Hasil ini tidak sesuai dengan penelitian Sutanto dan Japarianto (2013) menujukkan bahwa relationship marketing memiliki pengaruh yang positif dan signifikan dalam memberikan kepuasan kepada nasabah. Relationship marketing dalam penelitian ini difokuskan pada pemberian hadiah kepada nasabah BRI, sehingga tentu tidak semua nasabah BRI mendapatka hadiah yang jumlahnya terbatas sehingga para nasabah yang belum mandapatkan hadiah belum merasa puas terhadap relationship marketing yang dijalankan oleh BRI.

\section{CSR dan Kepuasan Nasabah}

Dari hasil uji statistik variabel CSR mempunyai signifikasi sebesar 0,897 yang berarti nilai siginfikasi kualitas layanan lebih besar dari 0,05 dengan nilai unstandardized coefficients beta sebesar 0,022 sehingga CSR tidak berpengaruh signifikan terhadap kepuasan nasabah. Hipotesis 3 ditolak karena tidak sesuai dengan hipotesis 3 yang menyatakan CSR berpengaruh positif signifikan terhadap kepuasan nasabah.

Hasil penelitian ini tidak sesuai dengan penelitian Nareeman dan Hassan (2013), mengungkapkan bahwa dampak CSR terhadap kepuasan pelanggan dan retensi menunjukkan bahwa CSR berpengaruh positif dan signifikan terhadap kepuasan. Luasnya cakupan wilayah menyebabkan kurang meratanya program CSR BRI hal ini menyebabkan program CSR yang dilakukan oleh BRI menjadi kurang maksimal. Akan tetapi BRI akan terus mening katkan program CSR di 


\section{Kualitas Layanan dan Loyalitas Nasabah}

Dari hasil uji statistik variabel kualitas layanan mempunyai signifikasi sebesar 0,000 yang berarti nilai siginfikasi kualitas layanan lebih kecil dari 0,05 dengan nilai unstandardized coefficients beta sebesar 0,064 sehingga variabel kualitas layanan berpengaruh signifikan positif terhadap loyalitas nasabah. Hipotesis 4 diterima dengan arah pengaruh positif, sesuai dengan hipotesis 4 yang menyatakan kualitas layanan berpengaruh positif signifikan terhadap loyalitas nasabah. Semakin besar nilai kualitas pelayanan maka akan semakin tinggi tingkat loyalitas nasabah.

Hasil penelitian ini sesuai dengan penelitian Akbar dan Parves (2009) menunjukkan terdapat hubungan yang positif dan signifikan antara kualitas pelayanan terhadap loyalitas pelanggan. Kumar et al. (2009) menyatakan bahwa kualitas pelayanan yang baik akan menghasilkan kepuasan pelanggan yang tinggi yang dapat meningkatkan loyalitas pelanggan. Program peningkatan layanan BRI terus memperbaiki dan meningkatkan kualiatas pelayanannya dengan mengembangkan proyek infrastruktur jaringan komunikasi - satelit BRI dan Fiber optik dengan membeli sebuah satelit yang diberi nama BRISAT yang kini sudah mengudara dan menjadikan BRI sebagai satu-satunya bank yang sudah memiliki satelit sendiri untuk memperlancar operasional perbankan.

\section{Relationship Marketing dan Loyalitas Nasabah}

Dari hasil uji statistik variabel Relationship Marketing mempunyai signifikasi sebesar 0,792 yang berarti nilai siginfikasi Relationship Marketing lebih besar dari 0,05 dengan nilai unstandardized coefficients beta sebesar 0,009 sehingga Relationship Marketing tidak berpengaruh signifikan terhadap loyalitas nasabah. Hipotesis 5 ditolak karena tidak sesuai dengan hipotesis 5 yang menyatakan Relationship Marketing berpengaruh positif signifikan terhadap loyalitas nasabah.

Hasil penelitian ini tidak sesuai dengan penelitian Peyman, Freyedon Ahmadi dan Motreza Fatehipoor (2013) yang menemukan bahwa relationship marketing berpengaruh terhadap loyalitas nasabah. Dari program relationship marketing yang dijalankan oleh BRI memang belum maksimal hal ini dikarenakan masih belum maksimalnya sosialisasi kepada para nasabah. Dalam penelitian ini program relationship marketing lebih difokuskan pada pemberian hadiah yang dilaksanakan oleh BRI. Tidak seimbangnya jumlah nasabah dan jumlah hadiah yang diberikan oleh BRI juga dapat menjadi faktor belum maksimalnya program relationship marketing yang dijalankan oleh BRI

\section{CSR dan Loyalitas Nasabah}

Dari hasil uji statistik variabel CSR mempunyai signifikasi sebesar 0,019 yang berarti nilai siginfikasi CSR lebih kecil dari 0,05 dengan nilai unstandardized coefficients beta sebesar 0,067 sehingga variabel CSR berpengaruh signifikan positif terhadap loyalitas nasabah. Hipotesis 6 diterima dengan arah pengaruh positif, sesuai dengan hipotesis 6 yang menyatakan CSR berpengaruh positif signifikan terhadap loyalitas nasabah. Semakin besar nilai CSR maka akan semakin tinggi tingkat loyalitas nasabah.

Hasil penelitian ini sesuai dengan penelitian Seravina (2008) yang menemukan bahwa tanggapan pelanggan terhadap aktivitas Corporate Social Responsibility memiliki pengaruh positif terhadap loyalitas pelanggan. Program CSR BRI Tebing Tinggi diantaranya adalah program jalan sehat dan kegiatan kemasyarakatan yang rata-rata diikuti oleh nasabah BRI. Sedangkan untuk bantuan sosial sering dilakukan dengan baksos di desa-desa yang banyak masyarakatnya merupakan masyarakat miskin dengan menjual paket bahan makanan dengan harga murah. 


\section{Kepuasan Nasabah dan Loyalitas Nasabah}

Dari hasil uji statistik variabel kepuasan nasabah mempunyai signifikasi sebesar 0,000 yang berarti nilai siginfikasi kepuasan nasabah lebih kecil dari 0,05 dengan nilai unstandardized coefficients beta sebesar 0,838 sehingga variabel kepuasan nasabah berpengaruh signifikan positif terhadap loyalitas nasabah. Hipotesis 7 diterima dengan arah pengaruh positif, sesuai dengan hipotesis 7 yang menyatakan kepuasan nasabah berpengaruh positif signifikan terhadap loyalitas nasabah. Semakin besar nilai kepuasan nasabah maka akan semakin tinggi tingkat loyalitas nasabah.

Hasil penelitian ini sesuai dengan Molaee et al. (2013) dan Anggraeni (2012) menyatakan bahwa kepuasan pelanggan berpengaruh positif dan signifikan terhadap loyalitas pelanggan. Kepuasan nasabah BRI mengakibatkan nasabah menjadi loyal hal ini dapat dilihat dari umur rekening nasabah yang sudah lama akan tetapi masih aktif digunakan oleh para nasabah BRI. Dari sekian banyak nasabah BRI merupakan nasabah yang sudah lama menggunakan jasa dari BRI, para nasabah lama umumnya merupakan pegawai negeri sipil untuk pengguna tabungan sedangkan untuk kredit lebih didominasi oleh petani sawit yang sejak lama telah menjalin kerjsama dengan BRI.

\section{SIMPULAN}

Penelitian ini bertujuan untuk memberikan bukti empiris tentang pengaruh Kualitas Iayanan, Relationship Marketing, Corporat Social Responsibility dan Kepuasan nasabah terhadap Loyalitas nasabah di BRI Cabang Tebing Tinggi. Dengan menggunakan 150 responden nasabah BRI cabang Tebing Tinggi tahun 2016. Berdasarkan hasil analisis dan pengujian hipotesis yang telah dilakukan maka hasil penelitian dapat disimpulkan sebagai berikut:

1. Variabel kualitas layanan mempunyai signifikasi sebesar 0,000 yang berarti nilai siginfikasi kualitas layanan lebih kecil dari 0,05 dengan nilai unstandardized coefficients beta sebesar 0,105 sehingga variabel kualitas layanan berpengaruh signifikan positif terhadap kepuasan nasabah.

2. Variabel Relationship Marketing mempunyai signifikasi sebesar 0,897 yang berarti nilai siginfikasi kualitas layanan lebih besar dari 0,05 dengan nilai unstandardized coefficients beta sebesar -0,007 sehingga variabel Relationship Marketing tidak berpengaruh signifikan terhadap kepuasan nasabah.

3. Variabel CSR mempunyai signifikasi sebesar 0,897 yang berarti nilai siginfikasi kualitas layanan lebih besar dari 0,05 dengan nilai unstandardized coefficients beta sebesar 0,022 sehingga CSR tidak berpengaruh signifikan terhadap kepuasan nasabah.

4. Variabel kualitas layanan mempunyai signifikasi sebesar 0,000 yang berarti nilai siginfikasi kualitas layanan lebih kecil dari 0,05 dengan nilai unstandardized coefficients beta sebesar 0,064 sehingga variabel kualitas layanan berpengaruh signifikan positif terhadap loyalitas nasabah.

5. Variabel Relationship Marketing mempunyai signifikasi sebesar 0,792 yang berarti nilai siginfikasi Relationship Marketing lebih besar dari 0,05 dengan nilai unstandardized coefficients beta sebesar 0,009 sehingga Relationship Marketing tidak berpengaruh signifikan terhadap loyalitas nasabah.

6. Variabel CSR mempunyai signifikasi sebesar 0,019 yang berarti nilai siginfikasi C SR lebih kecil dari 0,05 dengan nilai unstandardized coefficients beta sebesar 0,067 sehingga variabel CSR berpengaruh signifikan positif terhadap loyalitas nasabah.

7. Variabel kepuasan nasabah mempunyai signifikasi sebesar 0,000 yang berarti nilai siginfikasi kepuasan nasabah lebih kecil dari 0,05 dengan nilai unstandardized 
coefficients beta sebesar 0,838 sehingga variabel kepuasan nasabah berpengaruh signifikan positif terhadap loyalitas nasabah.

\section{Keterbatasan}

Penelitian ini memiliki beberapa keterbatasan yang dapat menyebabkan penarikan kesimpulan penelitian ini menjadi kurang sempurna. hal-hal tersebut adalah sebagai berikut:

1. Periode pengamatan penelitian ini terbatas dengan jumlah 150 responden yang menjadi sampel penelitian yang memiliki latar belakang pendidikan yang berbeda sehingga ada beberapa kendala dalam pengisian dari jawaban kuesioner.

2. Penelitian yang hanya difokuskan pada satu cabang BRI saja yaitu BRI cabang Tebing Tinggi dan tidak menentukan klasifikasi nasbah apakah nasabah tabungan atau nasabah pinjaman.

3. Hanya berfokus pada empat variabel saja yaitu Kualitas layanan, Relationship Marketing, Corporat Social Responsibility dan Kepuasan nasabah.

\section{Saran}

Berdasarkan hasil analisis dan pembahasan pengujian hipotesis penelitian ini, maka dapat disampaikan beberapa saran bagi penelitian selanjutnya dengan tema sejenis sebagai berikut:

1. Menambah jumlah sampel dan mengklasifikasikan nasabah BRI agar diperoleh hasil yang lebih signifikan sehing ga hasil penelitian lebih representatif.

2. Menambahkan jumlah kantor cabang BRI sehingga diperoleh hasil penelitian yang lebih spesifik.

3. Untuk penelitian selanjutnya, peneliti merekomendasikan untuk menambah variabel independen lainnya, mengingat bahwa model regresi yang digunakan dalam penelitian ini hanya mampu menjelaskan sebesar $70,2 \%$ saja atas variabel dependen.

\section{DAFTAR PUATAKA}

Agusta LR dan Dedy Baramulli. 2011. Pengaruh Kepercayaan dan Kepuasan Terhadap Loyalitas Nasabah. Jurnal Inovasi Manajemen. Vol. 8 No. 2.

Akbar, M.M., and Parvez, N. 2009. Impact of Services Quality, Trust, and Customer Satisfaction on Customer Loyalty. ABAC Journal, Vol. 29, No. 1, pp. 24-38.

Anggraeni, Savitri. 2012. Pengaruh E-Service Quality terhadap Kepuasan dan Loyalitas Pelanggan (Kasus Pada Pengguna Internet Banking di Commonwealth Bank Cabang Seminyak Bali). Tesis, Program Studi Magister Manajemen Universitas Udayana, Denpasar.

Bedi, M. 2010. An Integrated Framework for Service Quality, Customer Satisfaction and Behavioral Responses in Indian Banking Industry-a Comparison of Public and Private. Journal of Services Research, Vol. 10 No. 1, pp. 157-172.

Bowen, John T\& Shiang-Lih Chen.2001. The Relationship Between Customer Loyalty and Customer Satisfaction. International Journal of Contemporary Hospitality Management, Vol. 13, No. 5, pp. 213-217.

Chan, S. 2003. Relationship Marketing. Jakarta : Gramedia Pustaka Utama

Christina Widya Utami. 2006. Manajemen Ritel ( Strategi dan Implementasi Ritel Modern). Jakarta: Salemba Empat.

Griffin, Jill. 2008. Customer Loyalty How To Learn IT, How To Keep If. Mc. Grow.

Kotler, Philip and Garry Amstrong. 2008. Principle of Marketing, Prentice Hall Internasional. Inc : New Jersey.

Kotler, Philip. 2000. Marketing Management, Millenium Edition, Prentice Hall Internasional. Inc : New Jersey 
Kumar, M., Kee, F. T., and Manshor, A. T. 2009. Determining the Relative Importance of Critical Factors in Delivering Service Quality of Banks: an Application of Dominance Analysis in SERVQUAL Model. Managing Service Quality, Vol. 19, No. 2, pp. 211-228.

Ladhari, R., Ladhari, I., and Morales, M. 2011. Bank Services Quality: Comparing Canadian and Tunisian Customer Perceptions. International Journal of Bank Marketing, Vol. 29, No. 33, pp. 224-246.

Lupiyoadi Rambat. 2008. Manajemen Pemasaran Jasa. Salemba Empat Jakarta

Madjid, Rahmat. 2013. Customer Trust as Relationship Mediation Between Customer Satisfaction and Loyalty at Bank Rakyat Indonesia (BRI) Southeast Sulawesi. The International Journal of Engineering and Science, Vol. 2 No.5.

Ming, S.L., Huey, D.H., and Ming, F.Y. 2010. The Study of The Relationship Among Experiental Marketing, Services Quality, Customer Satisfaction and Customer Loyalty. International Journal of Organizational Innovation, pp. 352-378

Molaee, M., Ansari, and Telmouri, H. 2011. Analizing The Impact of Service Quality Dimensions on Customer Satisfaction and Loyalty in The Banking Industry of Iran. International Journal of Academic Research in Accounting, Finance and Management Sciences, Vol. 13, No. 3, pp. 5-13.

Naeem, H., and Saif, I. 2009. Service Quality and Its Impact on Customer Satisfaction: An Empirical Evidence from the Pakistani Banking Sector. The International Business and Economics Research Journal, Vol. 8, No. 12, pp. 99-104.

Ndubisi, N.O. and Chan, K.W. (2005) Factorial and discriminant analyses of the underpinnings of relationship. International Journal of Bank Marketing. 23(3): 542-57.

Ndubisi, N.O. (2007), "Relationship Marketing and Consumer Loyalty," Marketing Intelligence and Planning, Vol. 25, No. 1, pp. 98-106.

Odin, Y., N. Florence P. and Valette.2001. Conceptual and Operational Aspects Of Brand Loyalty, An Empirical Investigation. Journal of Business Research. 53. pp. 75-84.

Parasuraman. A., Zeithaml, V.A. and Berry, L.L, (1994), "Reassessment of Expectations as a Comparison Standar in Measuring Service Quality: Implication for Further Research, Journal of Marketing, January (58): 111-124 Principles, Sixth Edition, IRWIN, Chicago

Sanka, M.S. 2012. Bank Service Quality, Customer Satisfaction and Loyalty in Ethiopian Banking Sector, Journal of Business Administration and Management Sciences Research, Vol. 1, No. 1, pp. 001-009.

Silmi, Sulhida, 2012, Persepsi Nasabah Tentang Relationship Marketing dan Pengaruhnya Terhadap Loyalitas (Studi Pada Nasabah Tabungan Utama PT. Bank Mega Syariah Cabang Malang). Jurnal Manajemen Pemasaran, 8(1):1 14.

Sutanto. P. dan Japarianto. E. 2013. Analisa Pengaruh Service Quality, Price dan Customer Relationship Terhadap Customer Loyality dengan Customer Satisfaction Sebagai Variabel Intervening di Rumah Makan Taman Handayani. Jurnal Manajemen Pemasaran, 1(2): 19.

Tjiptono, F. 2004. Manajemen Jasa. Yogyakarta : Andi

Tjiptono, F. 2005. Pemasaran Jasa. Edisi Satu, Bayu Media Publishing: Malang

Yani, E. 2004. Analisis Pengaruh Kualitas Pelayanan terhadap Loyalitas Nasabah PT Bank Sumut di Medan, Tesis, Medan: Program Pascasarjana Universitas Sumatra Utara

Zafar, M., Zafar, S., dan Asif, A. 2012. Service Quality, Customer Satisfaction and Loyalty: An Empirical Analysis of Banking Sector in Pakistan, Information Management and Business Review, Vol. 4, No. 3, pp. 159-167. 